\title{
Use of A Novel Intraoral Device to Promote Nasal Breathing Reduces Risk of Tooth Decay in Children
}

\section{Toshi Hart*}

DDS, Toshi Hart DDS, Inc, 4213 Dale Rd B-6, Modesto, CA 95356, United States.

*Corresponding author: Toshi Hart, DDS, Toshi Hart DDS, Inc, 4213 Dale Rd B-6, Modesto, CA 95356, United States.
Received Date: April 22, 2021

Published Date: May 18, 2021

\begin{abstract}
Introduction: Tooth decay is a major issue for children, particularly disadvantaging those from low socioeconomic backgrounds, and has both physical and psychological repercussions. Treatment is expensive and unavailable for many children, making prevention essential. Mouth-breathing dries the mouth, reduces saliva flow rate and increases the presence of cariogenic bacteria that cause tooth decay. It is hypothesized that use of an intraoral device to promote nasal breathing may reduce the presence of tooth decay in children.

Methods: In a retrospective chart analysis of 80 children aged 4-12, children who were using an intraoral device (Vivos Guide, Vivos Therapeutics, Inc.) to promote nasal breathing were compared against those who had not used the device (control group). The device was worn passively at night and children were also asked to complete 2-4 hours of 'active wear' during the day, doing functional exercises with the tongue to promote nasal breathing. The presence of tooth decay was evaluated at six and twelve months and compared between the two groups.

Results: The subjects who used the intraoral device averaged 0.3 instances of tooth decay at six months and 0.4 instances at twelve months. Those who did not averaged 1.28 instances at six months and 0.95 at twelve months.

Discussion: Use of an intraoral device to promote nasal breathing significantly reduced the risk of tooth decay by $76.4 \%$ after six months ( $\mathrm{p}=$ $0.0004)$ and by $57.9 \%(\mathrm{p}=0.05)$ after twelve months. The device was well-tolerated by the subjects.

Conclusion: The study demonstrates use of an intraoral device to promote nasal breathing can reduce tooth decay and provides a novel method to supplement other means of prevention.
\end{abstract}

Keywords: Prevention of tooth decay; intraoral device; Vivos Guide; Nasal breathing

\section{Introduction}

\section{Prevalence}

Tooth decay in children is a painful, costly and widespread oral health problem. Overall, it is estimated that $3-6 \%$ of children in the United States have evidence of tooth decay [1], and the prevalence is significantly higher in socially disadvantaged communities $[2,3]$.

\section{Consequences for children}

Tooth decay has wide-ranging consequences for children. Cavities cause pain and discomfort within the mouth, influencing eating habits. In small children, tooth decay has been linked to reduced growth and weight gain [4]. Physically, poor oral health is associated with acute and chronic infections, abcesses, poor sleep, and gastrointestinal issues [5]. There is also a significant psychological component to oral health in children. Early tooth decay and cavities has been shown to impact self-esteem, feelings of well-being and socialization [6]. When causing tooth loss, decay has been linked to school absenteeism, inability to concentrate in school, failure to thrive, slowed speech development and lower selfesteem [7-9].

\section{Contributing factors to childhood tooth decay}

Research has identified the main contributing factors to childhood tooth decay, including the presence of cariogenic bacteria, 
diet, oral hygiene practices and the protective role of saliva. A primary culprit in the formation of tooth decay in children is the cariogenic bacteria Streptococcus mutans (SM). Within the mouth, this bacteria metabolizes sugars and produces acid which strips the enamel from teeth [10]. Research shows a clear link between SM and dental caries; in one study, children were five times more likely to have caries if they had a high level of SM found in the mouth.

S. mutans metabolizes sugars to create acidic byproducts, meaning diet plays a major role in tooth decay among children. Studies have shown a link between consumption of fermentable carbohydrates and tooth decay [11] and research indicates that the prevalence of dental caries drops in communities with lower sugar consumption [12]. Links have also been found between bottle habits, particularly sleeping with a bottle, are associated with tooth decay, with the theory that repeated, long-term exposure to sugars in the mouth promotes decay [13-15]. Proper oral hygiene can mitigate the effects of cariogenic bacteria and dietary influences. Unfortunately, not all children are educated in or have access to proper oral hygiene measures. Studies show that the socioeconomic status and education levels of caregivers has a substantial effect on the oral hygiene of children $[16,17]$. Consequently, research has shown children raised in low socioeconomic situations are twice as likely to have tooth decay as wealthier peers [18].

Saliva has a protective role to play in the mouth. It's the primary defense system against tooth decay. The saliva flow rate and properties of saliva are shown to prevent tooth decay [19]. Sugary foods at night, when the salivary flow rate is low, may be particularly dangerous in the formation of childhood tooth decay [20]. Mouth-breathing is associated with a dryer mouth, reducing the presence of saliva and its protective effects.

\section{Treatment}

Unfortunately, many children with pediatric tooth decay go untreated. Clinical management among children is often expensive because it necessitates the use of general anesthesia, with all the costs and associated risks [21]. In one study, researchers compared the effectiveness of three different treatment techniques among children. More than 1,000 children with tooth decay were randomized to either.

a) conservative care where they were given preventative recommendations about diet and oral hygiene,

b) standard 'drill and fill' techniques where the tooth decay is drilled out and replaced with a filling plus the same preventative recommendations, and

c) a less-invasive placement of a stainless-steel crown over the decayed area with the same preventative recommendations. The authors found no significant difference in outcomes between these three treatment methods [22].

\section{Mouth breathing as a risk factor}

Children who breath primarily through their mouth dry the mouth and reduce the presence of saliva. Mouth breathing is associated with higher levels of plaque and gingivitis. Studies have shown mouth breathing causes lower salivary flow rate and lower saliva $\mathrm{pH}$. Perhaps most importantly, research indicates higher levels of SM bacteria in the mouth for mouth-breathers than for nose-breathers [23].

\section{Study purpose and hypothesis}

It is clear preventative measures are preferable to having to treat tooth decay among children. However, despite widespread teaching of oral hygiene techniques, fluoridation of water supplies and toothpastes and other preventative measures, childhood tooth decay continues to be a major problem. This study aims to evaluate the ability of an intraoral device designed to convert children from mouth-breathing to nose-breathing to reduce the risk of tooth decay. If the device is able to prevent mouth-breathing, it may be able to increase salivary factors, reduce the presence of cariogenic bacteria and, ultimately, reduce childhood tooth decay. The study will be conducted in an area with unfluoridated water supplies (indicating children at higher risk for tooth decay). Children who are in need of the intraoral positioner for jaw alignment, closed airways, snoring, bedwetting behaviors, or other reasons will also be monitored for tooth decay to determine whether an intraoral positioning device can reduce the risk of tooth decay.

\section{Methods}

This study is a retrospective chart analysis of 80 children, aged 4-12, who received treatment at a single dental clinic. Half of the patients (40) had been given an intraoral device to treat sleepdisordered breathing or other oral issues, while half (40) had not.

\section{Preventative education}

Both groups received the same information on measures to prevent tooth decay, including proper oral hygiene and dietary considerations.

\section{Intraoral device}

The intraoral device (Vivos Guide, Vivos Therapeutics, Inc.) is a flexible, mono-block, BPA-free polymer plastic device designed to reposition the jaw and seal the lips to convert mouth-breathing children to nose-breathing. The device is worn by the children throughout the night as they sleep for 8-10 hours of passive wear each day. There is also an active use component where the child actively conducts myofunctional exercises of the mouth with the device in for 2-4 hours during the day. The tongue is raised to the roof of the mouth, effectively closing the lips and retraining the body to breathe through the nose.

\section{Study outcomes}

Both children in the test group and the control group were evaluated for the formation of tooth decay. If tooth decay was found, it was treated. Then children were followed up at six and twelve months. If found at six months, tooth decay was again treated (so the check at twelve months measured new decay that formed between 6-12 months). 


\section{Results}

\section{Demographics}

There was no significant difference between the control and test groups in either age or gender. The average age for both groups was 8.38 years of age (STD of 1.97 in the test group and 1.90 in the control group). The control group had 20 male and 20 female children, while the test group had 19 male and 21 female children.

\section{Study results}

Table 1: Average Instances of Tooth Decay Per Child at 6 Months of Device Use.

\begin{tabular}{|c|c|c|}
\hline & Test & Control \\
\hline Average Instances of Tooth Decay & 0.3 per child (SD 0.72) & 1.28 per child (SD 1.61) \\
\hline Risk Reduction & $76.40 \%$ & \\
\hline
\end{tabular}

Table 2: Average Instances of Tooth Decay Per Child at 12 Months of Device Use.

\begin{tabular}{|c|c|c|}
\hline & Test & Control \\
\hline Average Instances of Tooth Decay & 0.4 per child (SD 0.87) & 1.28 per child (SD 1.90) \\
\hline Risk Reduction & $57.90 \%$ & \\
\hline
\end{tabular}

At six months, subjects in the test group averaged 0.3 instances of tooth decay on examination, ranging from 0 to a maximum of 3 areas of tooth decay found. The control group averaged 1.28 instances with a range from 0 to a maximum of 6 areas of tooth decay per child. At twelve months, subjects in the test group averaged 0.4 instances of tooth decay, ranging from 0 to 4 areas found. The control group averaged 0.95 instances of tooth decay, ranging from 0 to 9 per child (Table 1,2). The device was welltolerated by children, with no reported complaints from children or their caregivers.

\section{Discussion}

The data indicate a statistically significant reduction in the risk of development of tooth decay at both six and twelve months when using an intraoral device to promote nasal breathing. At six months, risk of tooth decay was reduced by $76.4 \%(p=0.0004)$ and at twelve months the risk reduction was $57.9 \%(p=0.05)$.

An unpaired (independent) two-sample t-test was used for statistical analysis to compare the means of the control and treatment groups. The null hypothesis that there was no significant difference between the test groups was rejected and the difference in means was deemed statistically significant at a $95 \%$ confidence level.

While the mechanism of action was not investigated in this study, there are two possibilities that appear likely based on previous research and the results obtained in this study. The first is children were converted from mouth-breathing to nose-breathing. This increased the saliva levels in the mouth, increasing the $\mathrm{pH}$ of the mouth and decreasing the prevalence of cariogenic bacteria causing decay. It is also possible that converting patients to nosebreathing increased levels of nitric oxide in the nasal cavities and positively affected the oral environment to reduce cariogenic bacteria levels.

\section{Conclusion}

Use of an intraoral device promoting nasal breathing among children showed significant reductions in the risk of tooth decay among children aged 4-12 after six and twelve months of use. Additional research into the mechanism of action and whether these protective effects are maintained after use of the device is discontinued is warranted. This research demonstrates a novel technique for preventing tooth decay among children.

\section{Acknowledgement}

The author wishes to thank and acknowledge Aaron B. Stevens BSPE, PES.

\section{Conflicts of Interest}

The author declares no conflicts of interest.

\section{References}

1. Horowitz HS (1998) Research issues in early childhood caries. Community Dent Oral Epidemiol 26(1 Suppl): 67-81.

2. Ismail AI, Lim S, Sohn W, Willem JM (2008) Determinants of early childhood caries in low-income African American young children. Pediatr Dent 30(4): 289-296.

3. Vachirarojpisan T, Shinada K, Kawaguchi Y, Laungwechakan P, Somkote T, et al. (2004) Early childhood caries in children aged 6-19 months. Community Dent Oral Epidemiol 32(2):133-142.

4. Petersen PE, Estupinan Day S, Ndiaye C (2005) WHO's action for continuous improvement in oral health. Bull World Health Organ 83: 642 .

5. Nunn ME, Braunstein NS, Krall Kaye EA, Dietrich T, Garcia RI, et al. (2009) Healthy eating index is a predictor of early childhood caries. J Dent Res 88(4): 361-366

6. Locker D (1977) Concepts of oral health, disease and the quality of life. In: Slade GD, editor. Measuring oral health and quality of life. Chapel Hill: University of North Carolina, Dental Ecology pp: 11-23.

7. Acs G, Lodolini G, Kaminsky S, Cisneros GJ (1992) Effect of nursing caries on body weight in a pediatric population. Pediatr Dent 14: 302-305

8. Acs G, Shulman R, Ng MW, Chussid S (1999) The effect of dental rehabilitation on the body weight of children with early childhood caries. Pediatr Dent 21: 109-113.

9. Acs G, Lodolini G, Shulman R, Chussid S (1998) The effect of dental rehabilitation on the body weight of children with failure to thrive: Case reports. Compend Contin Educ Dent 19: 164-168.

10. Senesombath S, Nakornchai S, Banditsing P, Lexomboon D (2010) Early childhood caries and related factors in Vientiane, Lao PDR. Southeast Asian J Trop Med Public Health 41(3): 717-725. 
11. Paglia L, Scaglioni S, Torchia V, De Cosmi V, Moretti M, et al. (2016) Familial and dietary risk factors in early childhood caries. Eur J Paediatr Dent 17(2): 93-99.

12. (2003) Diet, nutrition and the prevention of chronic diseases. (1-149). World Health Organ Tech Rep Ser 916: i-vii. backcover.

13. Azevedo TD, Bezerra AC, de Toledo OA (2005) Feeding habits and severe early childhood caries in Brazilian preschool children. Pediatr Dent 27: 28-33.

14. Hallett KB, O’Rourke PK (2002) Early childhood caries and infant feeding practice. Community Dent Health 19: 237-242.

15. Oulis CJ, Berdouses ED, Vadiakas G, Lygidakis NA (1999) Feeding practices of Greek children with and without nursing caries. Pediatr Dent 21: 409-416.

16. Ramos Gomez FJ, Weintraub JA, Gansky SA, Hoover CI, Featherstone JD (2002) Bacterial, behavioral and environmental factors associated with early childhood caries. J Clin Pediatr Dent 26(2): 165-173.

17. Aida J, Ando Y, Aoyama H, Tango T, Morita M (2006) An ecological study on the association of public dental health activities and sociodemographic characteristics with caries prevalence in Japanese 3-year-old children. Caries Res 40(6): 466-472.
18. Gaur S, Nayak R (2011) Underweight in low socioeconomic status preschool children with severe early childhood caries. J Indian Soc Pedod Prev Dent 29(4): 305-309.

19. Jiang S, Gao X, Jin L, Lo EC (2016) Salivary microbiome diversity in caries-free and caries-affected children. Int J Mol Sci 17(12): 1978.

20. Silva PV, Troiano JA, Nakamune AC, Pessan JP, Antoniali C (2016) Increased activity of the antioxidants systems modulate the oxidative stress in saliva of toddlers with early childhood caries. Arch Oral Biol 70: 62-66.

21. Duangthip D, Jiang M, Chu CH, Lo EC (2016) Restorative approaches to treat dentin caries in preschool children: systematic review. Eur J Paediatr Dent 17(2): 113-121.

22. NP Innes, JE Clarkson, GVA Douglas, V Ryan, N Wilson, et al. (2019) Child Caries Management: A Randomized Controlled Trial in Dental Practice. J Dent Res 99(1): 36-43.

23. AlAwadi R, AlCasey M (2013) Oral health status, salivary physical properties and salivary Mutans Steptococci among a group of mouth breathing patients in comparison to nose breathing. J Bagh College Dentistry 25(1). 